\title{
ANALISA STABILITAS CHECKDAM PABYONGAN DESA MULYOSARI KECAMATAN PAGERWOJO KABUPATEN TULUNGAGUNG
}

\author{
Jarno Sutikno *1, Ahmad Ridwan ${ }^{2}$, Yosef Cahyo SP. ${ }^{3}$ \\ ${ }^{1,2,3}$ Fakultas Teknik, Universitas Kadiri. \\ e-mail:*1 sutikna.granat99@gmail.com,2ahmad ridwan@unik-kediri.ac.id, \\ 3 yosef.cs@unik-kediri.ac.id.
}

\begin{abstract}
Checkdam is a control building created due to the presence of water flow with a large enough sediment concentration. Plan to build the Kali Wangi Check dam is one of the flood mitigation efforts that caused severe damage to several drainage structures. Selection of the type of dam is based on the geological conditions of the location where the Check dam is to be built, namely the subgrade in the form of sand, rocky gravel which is also the same on the cliffs, so the type of dam used is the Gravity Type, the pair of river stones with a mixture of 1: 4 outer and The surface is spread with a 1:2 mixture with a thickness of $2 \mathrm{~cm}$, for the inside using a 1: 3 mixture this mixture is used for the dam and the apron. It is hoped that it can provide a maximum and sturdy function, for that the dam must be subjected to strength control from several aspects, namely control of rolling, shear, soil bearing capacity, and water lifting force on the dam body. From the calculation, it is concluded that the Kali Wangi Check dam is strong withstand the forces acting on it.
\end{abstract}

Keywords : $\quad$ Checkdam, Stability Control, Safety Factor, Discharge Plan

\begin{abstract}
Abstrak
Checkdam adalah bangunan pengendali yang dibuat karena adanya aliran air dengan konsentrasi sediment yang cukup besar. Rencana pembuatan Checkdam Kali Wangi ini merupakan salah satu usaha penanggulangan banjir yang mengakibatkan kerusakan yang parah pada beberapa bangunan pengaliran. Pemilihan type dam di dasarkan pada kondisi geologi lokasi calon dibangunnya Checkdam, yaitu tanah dasar berupa tanah pasir, kerikil berbatu yang juga sama pada tebing-tebingnya, maka type dam yang dipakai adalah Type Gravitasi, Pasangan batu kali dengan campuran $1: 4$ bagian luar dan permukaan disiar dengan campuran $1: 2$ dengan tebal $2 \mathrm{~cm}$, untuk bagian dalam menggunakan campuran $1: 3$ campuaran ini digunakan untuk bagian dam dan apronnya. Diharapkan dapat memberikan fungsi yang maksimal dan kokoh, untuk itu pada dam harus diadankan pengontrolan kekuatan dari beberapa aspek yaitu kontrol terhadap guling, geser, daya dukung tanah maupun gaya angkat air pada tubuh dam. Dari hasil perhitungan disimpulkan bahwa Checkdam Kali Wangi ini kuat menahan gaya-gaya yang bekerja padanya.
\end{abstract}

Kata Kunci : Checkdam, Control Stabilitas, Faktor Keamanan, Debit Rencana 


\section{PENDAHULUAN}

Standar untuk perhitungan khusus dalam perencanaan checkdam sampai saat ini belum dibukukan, dalam Tinjauan Pustaka Laporan Tugas Akhir ini berdasarkan pada bahan materi yang diambil dari buku refrensi yang menyangkut perencanaan bangunan checkdam. Check dam adalah bangunan pengendali yang dibuat karena adanya aliran air dengan konsentrasi sediment yang cukup besar, dimana sedimen tersebut berasal dari erosi tanah pada bagian hulu sungai, [1]. Hal pokok lain dalam perencanaan check dam adalah sejauh mana sediment yang larut mampu ditahan oleh bangunan ini.

Prinsip stabilitas bangunan check dam terhadap gaya guling, gaya geser, yang ada pada bangunan untuk mencegah kerusakan yang diakibatkan aliran air dan sediment sangat penting.Pemilihan lokasi check dam harus tepat arena daya dukung tanah sangat berperan penting dalam stabilitas bangunan checkdam. Pertimbangan lain dengan adanya perencanaan check dam ini adalah jika dipandang dari segi ekonomis biaya pembngunan dan perawatan tidak terlalu mahal dan dari segi keamanan artinya aman untuk konstruksi itu sendiri yaitu bangunan mampu menahan aliran sediment,.

Erosi dan sedimentasi merupakan dua buah masalah yang saling berkaitan. Erosi tanah yang meliputi proses pelepasan butiran - butiran tanah dan proses pemindahan tanah akan menyebabkan timbulnya bahan endapan atau sedimentasi ditempat lain[2][3]. Pada saat permulaan turun hujan, pukulan jatunya air hujan merupakan penghasil utama butiran - butiran yang lepas dalam proses erosi tanah. Bersama dengan aliran air, butiran-butiran tanah yang lepas akibat

proses erosi akan diangkut masuk kedalam aliran sungai dan kemudian akan diendapan pada tempat-tempat tertentu berupa endapan / sedimentasi [4]. Endapan sedimentasi tersebut apabila semakin lama semakin terakumulasi jumlahnya, maka akan menimbulkan pendangkalan pada waduk dan muara sungai yang selanjutnya akan berakibat terhadap berkurangnya umur rencana waduk. Banyaknya angkutan bahan endapat tergantung dari besarnya erosi tanah yang terjadi. Semakain banyak jumlah bahan sedimen yang terangkut menunjukan makin besarnya tingkat erosi tanah yang terjadi dalam daerah aliran sungai yang bersangkutan, [5][6]. Karena erosi dan sedimentasi merupakan suatu hal yang saling memilik keterkaitan, maka dibawah ini akan dibahas kedua masalah tersebut. Berdasarkan hal tersebut maka penulis mengangkat judul " Analisa Stabilitas Checkdam Pabyongan Desa Mulyosari Kecamatan Pagerwojo Kabupaten Tulungagung ". [7]

Batasan yang digunakan pada penelitian ini adalah untuk meminimalkan efek negatif dari banjir yang terjadi, maka diperlukan perencanaan sebuah bangunan checkdam di Kali 
Wangi, lingkup pembahasannya dibatasi hanya sampai pada perhitungan estimasi daya tampung sedimen, yang tepatnya sebagai berikut :

(1) Analisa Hidrologi Check Dam Kali Wangi

(2) Perencanaan Dimensi Check Dam Kali Wangi

(3) Kontrol terhadap stabilitas Check Dam Kali Wangi

(4) Perhitungan daya tampung sedimen / material.

(5) Tidak menghitung Rencana Anggaran Biaya ( RAB ).

\section{METODE PENELITIAN}

\subsection{Analisa Perhitunga Besar Curah Hujan}

1) Meotde Gumbel

Analisa ini digunakan untuk menghitung besarnya curah hujan rata-rata yang mungkin terjadi di area stasiun pengamatan hujan dilingkup daerah sekitar, [8][9]. Hasil perhitungan curah hujan rata-rata direncanakan untuk kala ulang 20 tahun kedepan.

2) Metode Log Pearson Type I II

Analisa ini digunakan untuk menghitung besarnya curah hujan yang mungkin terjadi di suatu daerah dengan peluang kejadian tertentu. Hasil perhitungan curah hujan rancangan untuk kala ulang 20 tahun

\subsection{Analisa Debit Banjir Rencana}

Untuk mengetahui debit banjir rencana yang digunakan untuk menentukan data curah hujan yang mungkin terjadi dalam periode ulang tertentu[10]. Periode ulang yang dipakai dalam merencanakan bangunan checkdam Kali Wangi adalah 20

Tahun (R20), sedangkan untuk menghitung besarnya debit rencana dipakai metode sebagai berikut : Metode Rasional, Metode Log Pearson Type III

1) Metode Rasional

Analisa ini digunakan untuk menghitung besarnya perkiraan debit rencana banjir yang mungkin terjadi di suatu daerah dengan luas aliran DAS dan intensitas hujan efektif setiap jam-nya. Direncanakan untuk kala ulang 20 tahun (R20).

Metode Rasional dapat digunakan untuk menghitung debit puncak sungai atau saluran, namun dengan daerah pengaliran yang terbatas.

Rumus umum dari Metode Rasional adalah :

$\mathrm{Q}=0,278 \times \mathrm{C} \times \mathrm{I} \times \mathrm{A}$

Keterangan :

$\mathrm{Q}=$ debit puncak limpasan permukaan $\left(\mathrm{m}^{3} / \mathrm{det}\right)$.

$\mathrm{C}=$ angka pengaliran (tanpa dimensi) 
A = luas daerah pengaliran $\left(\mathrm{km}^{2}\right)$

$\mathrm{I}=$ intensitas curah hujan ( $\mathrm{mm} / \mathrm{jam})$.

Metode Rasional bisa dikembangkan dengan asumsi sebagai berikut :

- Hujan yang terjadi mempunyai intensitas yang seragam dan merata di seluruh daerah pengaliran selama paling sedikit sama dengan waktu konsentrasi (tc) daerah pengaliran.

- Periode ulang debit sama dengan periode ulang hujan.

- Koefisien pengaliran dari daerah pengaliran yang sama adalah tetap untuk berbagai periode ulang.

2) Metode Log Pearson Type III

Analisa ini digunakan untuk menghitung besarnya debit banjir rencana yang mungkin terjadi di suatu daerah dengan intensitas hujan rata-rata selama waktu tiba terjadinya banjir. Direncanakan untuk kala ulang 20 tahun (R20).

\subsection{Analisa Perencanaan}

Kriteria yang sangat menentukan diantara dua type checkdam sesuai dengan usahan pengendalian sedimen adalah berdasarkan tinggi efektif (efektif tampungan) dari checkdam yang direncanakan [11][12]. Adapun kriteria tersebut adalah sebagai berikut : Tinggi efektif $(\mathrm{H}) \leq 15$ $m$ dipakai type gravitasi. Tinggi efektif $(\mathrm{H}) \geq 15 \mathrm{~m}$ dipakai type arch. Dengan demikian dalam perencanaan checkdam Kali Wangi, apabila ditinjau dari tebing sungai, dimana letak kedudukan checkdam tersebut dapat dikatakan relatif rendah, lagi pula tebing - tebingnya merupakan tanah yang kurang dapat menjamin ujung daripada bangunan ( bila dipakai type arch ), sehingga direncanakan type gravitasi yang tinggi efektif $\leq 15$ meter.

\subsection{Perencanaan Dimensi Checkdam}

Perencanaan dimensi checkdam meliputi beberapa bagian antara lain :

1. Checkdam

Tampang Checkdam

Peluapan checkdam

Sayap

Drip hole

2. perencanaan lantai kolam olah

3. Perkuatan kaki

\section{$2.5 \quad$ Kontrol Stabilitas Checkdam}

Begitu besar manfaat dan fungsi dari pada bangunan checkdam yang akan dibuat, maka bangunan checkdam harus kuat menahan gayagaya yang bekerja pada bangunan tersebut. Untuk dapat menahan gayagaya yang bekerja pada bangunan checkdam tersebut, pembuatan checkdam disini memakai andalan utama berupa berat dari tubah checkdam itu sendiri, [13][14]. Sehingga 
besar kecilnya dimensi checkdam serta kekuatan tanah dasar kedudukan checkdam berada sangat menentukan stabilitas bangunan itu sendiri, [15][16]. Dari hasil perencanaan dimensi checkdam sesuai dengan yang telah dibahas maka pada bab ini akan dibahas kestabilan khusus tubuh checkdam yang akan direncanakan.

1. Gaya-gaya Yang Bekerja

Dalam menghitung stabilitas checkdam, diperlukan perhitungan gayagaya yang bekerja sesuai dengan tinggi checkdam maupun keadaan Air yang mengalir, dapat dilihat pada table

Tabel 1 Gaya-gaya yang berkerja

\begin{tabular}{|l|l|l|}
\hline Tinggi & Muka Air Normal & Muka Air Banjir \\
\hline \multirow{3}{*}{$\mathrm{H} \leq 15 \mathrm{~m}$} & & Berat Sendiri \\
\cline { 3 - 3 } & & Tekanan air statis \\
\hline \multirow{3}{*}{$\mathrm{H} \geq 15 \mathrm{~m}$} & Berat Sendiri & Berat Sendiri \\
\cline { 2 - 3 } & Tekanan Hidrostatis & Tekanan Hidrostatis \\
\cline { 2 - 3 } & Tekanan Sedimen & Tekanan Sedimen \\
\cline { 2 - 3 } & Tekanan Keatas & Tekanan Keatas \\
\cline { 2 - 3 } & Tekanan Hidrodinamis & \\
\cline { 2 - 3 } & Gaya Gempa & \\
\hline
\end{tabular}

\section{Perhitungan Berat Sendiri Checkdam}

Perhitungan berat sendiri diambil pada posisi yang paling rawan, yaitu pada posisi dibawah mercu checkdam. Pengukuran berat volume pada drip hole tidak diperhitungkan, karena pada saat sedimen telah rata dengan ambang bawah mercu checkdam, lubang-lubang drip hole telah terisi penuh oleh batuan dan sedimen dan berat volumenya mendekati harga pasangan, [17][18].

\section{Gaya Tekan Air Statis}

Tekanan air statis ini dihitung pada saat banjir yang mana tinggi air banjir adalah 2,00 m diatas ambang bawah mercu checkdam. Tekanan air statis ini mempengaruhi besar gaya tekan air.

\section{Gaya Tekan Sedimen}

Tekanan sedimen dihitung pada anggapan kondisi rata amabang bawah mercu checkdam, yang mana tekanan sedimen mempengaruhi besar gaya tekan sedimen terhadap checkdam.

\section{Gaya Tekan Ke Atas (Up Lift)}

Gaya tekan ke atas oleh air pada sepanjang dasar checkdam perlu dipertimbangkan, yang mana gaya angkat ini mengurangi kekokohan checkdam dalam menekan tanah

\section{Kontrol Kekuatan Checkdam}

Untuk mengetahui kekuatan daripada checkdam didalam menahan segala gaya yang ditahannya, serta untuk mengetahui apakah tanah dasar tempat kedudukan checkdam juga mampu menahan seluruh beban yang dipikulnya, maka perlu adanya analisa perhitungan pada stabilitas 
terhadap gaya penggulingan, pergeseran, serta perhitungan terhadap tegangan tanah yang terjadi, [19][20]. Beberapa kontrolnya adalah sebagai berikut :

- Kontrol Stabilitas Terhadap Guling.

- Kontrol Stabilitas Terhadap Geser.

- Kontrol Stabilitas Terhadap Pondasi.

- Kontrol Tebal Lantai Apron Terhadap Gaya Up Lift.

7. Estimasi Daya Tampung Sedimen

Dalam laporan tugas akhir ini perencanaan checkdam dimaksudkan sebagai bangunan pengendali sedimen, yang mana aliran debris yang banyak membawa sedimen yang ada di daerah tebing-tebing sungai tidak menjadi longsor dan curam. Sedimen yang terbawa aliran tersebut akan tertahan dibagian hulu checkdam, sebagian lagi juga masih terbawa ke daerah yang lebih rendah. Besarnya kemiringan dasar sungai asli (Io) dan kemiringan dasar sungai rencana (Ir). Beberapa Estimasi daya tampung sedimen adalah sebagai berikut :

1. Estimasi Daya Tampung Sedimen Tetap (Statis)

2. Estimasi Daya Tampung Sedimen Total

3. Estimasi Daya Tampung Sedimen yang Dapat Diatur

\subsection{Tahapan Pelaksanaan}

Metode pengumpulan data pada penelitian ini meliputi data primer dan sekunder. Data primer adalah data yang diperoleh dengan cara survey dan pengukuran lapangan, meliputi sebagai berikut :

- Topografi lokasi bangunan

- Penutupan lahan dan pola tanam

- Tanah (jenis, tekstur, permeabilitas)

- DTA

- Jumlah, kepadatan dan pendapatan penduduk dan tingkat harga/upah disekitar lokasi

Sedangkan data sekunder adalah data yang dapat diperoleh dengan cara pengumpulan data yang telah ada/tersedia baik di instansi pemerintah, swasta, dan lain sebagainya. Data sekunder meliputi :

- Administrasi wilayah

- Curah hujan (jumlah, intensitas dan hari hujan)

- Erosi dan sedimentasi

- Adat istiadat masyarakat disekitar lokasi 


\section{HASIL DAN PEMBAHASAN}

Curah Luas hujan berdasarkan perhitungan dengan menggunakan Metode Log Pearson Type III pada R20 adalah sebesar $100 \mathrm{~mm}$, sedangkan DebitBanjir Rencana berdasarkan perhitungan dengan menggunakan Metode Rasional dalam periode ulang 20 tahun yaitu sebesar $167 \mathrm{~m}^{3} / \mathrm{dt}$.

\subsection{Dimensi Checkdam}

\section{Checkdam}

1. Tinggi total $=11,50 \mathrm{~m}$

2. Tinggi sayap checkdam $=2,08 \mathrm{~m}$

3. Lebar mercu checkdam $=42,557 \mathrm{~m}$

4. Tebal mercu checkdam $=3,00 \mathrm{~m}$

5. Tebal pondasi $=11,05 \mathrm{~m}$

6. Kemiringan tubuh bagian hulu $=1: 50$

7. Kemiringan tubuh bagian hilir $=1: 20$

\subsection{Kolam Olak}

1.Panjang apron $=18,00 \mathrm{~m}$

2. Lebar dibagian hulu $=48,157 \mathrm{~nm}$

3. Lebar dibagian hilir $=42,557 \mathrm{~m}$

4. Tebal apron $=1,14 \mathrm{~m}$

\subsection{Kontrol Stabilitas Checkdam}

1. Kontrol Stabilitas Terhadap Guling

Syarat posisi $\mathrm{x}$ adalah $=1 / 3 \mathrm{~b} 2 \leq \mathrm{x} \leq 2 / 3 \mathrm{~b} 2$;

Maka dari hitungan diatas $=3,683 \leq 4,624 \leq 7,367 \quad$ (ok).

2. Kontrol Stabilitas Terhadap Geser

Sf : Angka keamanan $(\mathrm{Sf}=1,2)$ Sehingga 314,75/160,65 x 0,754 x 1,460 $\geq 1,20$ (Aman)

3. Kontrol Stabilitas Terhadap Pondasi

$\sigma=60 \mathrm{t} / \mathrm{m}^{2}$

$\sigma_{2}=167,7 / 7,298(1-(6 \times 0,143 / 7,298))=25,684 \mathrm{t} / \mathrm{m}^{2}>60 \mathrm{t} / \mathrm{m}^{2}(\operatorname{aman})$

4. Kontrol Tebal Lantai Apron Terhadap Gaya Up Lift

Berat pasangan $(\mathrm{G})=1,00 * 1,00 * 1,14 * 2,20=2,508 \mathrm{t} / \mathrm{m}$

$\mathrm{Ux}=\mathrm{Uc}=2,25 \mathrm{t} / \mathrm{m} \mathrm{G} \geq \mathrm{Uc}=2,508 \geq 2,25 \quad$ (aman).

\subsection{Kemampuan Daya Tampung}

1. Daya tampung sedimen total $=700.692,042 \mathrm{~m}^{3}$

2. Daya tampung sedimen tetap $=525.519,031 \mathrm{~m}^{3}$ 
3. Daya tampung sedimen yang dapat diatur $=175.173,011 \mathrm{~m}^{3}$

\subsection{Debit Rencana (Q20)}

Dengan direncanakan Checkdam Kali Wangi yang berlokasi di Desa Mulyosari

Kecamatan Pagerwojo Kabupaten Tulungagung ini dapat memberikan manfaat sebagai berikut :

1. Mengurangi jumlah sedimen yang masuk ke checkdam Kali Wangi.

2. Memberi pengamanan daerah pertanian disekitar Desa Mulyosari

3. Kecamatan Pagerwojo Kabupaten Tulungagung yang terancam erosi terutama yang disekitar Checkdam Kali Wangi.

4. Menstabilkan dasar dan mengarahkan aliran sungai.

5. Menahan objek mata pencarian penduduk setempat dari tampungan sedimen yang berupa pasir, kerikil, batu sebagai bahan bangunan.

\section{KESIMPULAN}

1. Pada prinsipnya perencanaan checkdam ini adalah untuk mencegah dan mengurangi bencana akibat aliran sedimen (debris) yang dirumuskan sedemikian rupa sehingga dapat normal dan efektif ditinjau dari dua sudut pengendalian banjir dan pengembangan sungai. Maka dalam perencanaan checkdam ini harus mempunyai analisa perencanaan meliputi :

a. Analisa Penyebab Banjir Analisa Hidrologi

b. Analisa perencanaan curah hujan

c. Analisa debit rencana banjir

d. Menentukan periode kala ulang jangka 20 tahun untuk checkdam

e. Perencanaan Dimensi Checkdam

f. Kontrol Stabilitas Checkdam

g. Estimasi Daya Tampung Sedimen

2. Curah hujan berdasarkan perhitungan dengan menggunakan Metode Log Pearson Type III pada R20 adalah sebesar $100 \mathrm{~mm}$ 3)

3. Debit Banjir Rencana berdasarkan perhitungan dengan menggunakan Metode Rasional dalam periode ulang 20 tahun yaitu sebesar $167 \mathrm{~m} 3 / \mathrm{dt}$.

\section{SARAN}

Berdasarkan Kesimpulan diatas maka diajukan beberapa saran yaitu perlu penelitian lebih lanjut terhadap kestabilan checkdam untuk tahun- tahun mendatang

\section{UCAPAN TERIMAKASIH}

Dalam penyusunan artikel ini, penulis ucapkan terimakasih kepada dosen pembimbing dan Universitas Kadiri. Penulis berharap agar artikel ini dapat bermanfaat bagi pembaca. 


\section{DAFTAR PUSTAKA}

[1] Suhudi and E. R. D. Kandari, "UJI STABILITAS CHECK DAM KEDUNGREJO 15 DI KALI KONTO KECAMATAN PUJON KABUPATEN MALANG,” J. Reka Buana, vol. 1, no. 2, pp. 65-72, 2016.

[2] [Kementerian PUPR]. Kementerian Pekerjaan Umum dan Perumahan Rakyat, PERENCANAAN BANGUNAN UTAMA (BENDUN. 2016.

[3] I. Yusup, G. Noor, J. Sulistian, and T. Rosdiyani, "PERENCANAAN CHECKDAM NOMOR DUA DI SUNGAI CIMAUR CIPANAS KABUPATEN LEBAK BANTEN,” vol. 1, no. 1, 2018.

[4] [Kementerian PUPR]. Kementerian Pekerjaan Umum dan Perumahan Rakyat, PANDUAN PERENCANAAN BEND URUGAN VOL 2. ANALISIS HIDROLOGI. .

[5] N. M. Propezite and Z. M Nur, "PERENCANAAN CHECK DAM SUNGAI PIJI KABUPATEN KUDUS.” Diponegoro University, 2015.

[6] C. Soemarto, "Hidrologi Teknik," Usaha Nas. Surabaya, 1987.

[7] [Kementerian PUPR]. Kementerian Pekerjaan Umum dan Perumahan Rakyat, PERENCANAAN DIMENSI BANGUNAN SABO, vol. 42, no. 4. 2005.

[8] Soewarno, HIDROLOGI JILID 1. 1995.

[9] A. T. Kusuma, D. Wijayanti, P. S. Atmodjo, and S. Edhisono, "PERENCANAAN CHECK DAM SUNGAI GLUGU KABUPATEN GROBOGAN, JAWA TENGAH,” $J$. KARYA Tek. SIPIL, vol. 4, no. 4, 2015, doi: 10.1017/CBO9781107415324.004.

[10] L. Herlina and E. Kurniyaningrum, "ANALISIS STABILITAS BANGUNAN PENGENDALI SEDIMEN (SABO DAM) BERDASARKAN MORFOLOGI SUNGAI DI SUNGAI WARMARE, KABUPATEN MANOKWARI," J. Sipil, vol. 13, no. 1, pp. $1-8,2013$.

[11] Soewarno, HIDROLOGI JILID 2. 1995.

[12] A. C. Nugroho, H. Mudhofar, S. Sangkawati, and D. Kurniani, "Perencanaan Check Dam Galeh Kabupaten Temanggung,” J. Karya Tek. Sipil, vol. 4, no. 4, pp. 13-20, 2015.

[13] Soedibyo, "Teknik Bendungan," 2003.

[14] Y. R. Illahi and Sumiadi, "PERENCANAAN CHECK DAM AMPELGADING SEBAGAI UPAYA PENGENDALIAN BANJIR LAHAR DINGIN GUNUNG SEMERU PADA SUNGAI GLIDIK KECAMATAN TEMPURSARI KABUPATEN LUMAJANG."

[15] Sugito, "PERENCANAAN CHECK DAM WAY RAREM DI KABUPATEN LAMPUNG UTARA," J. Tek. Sipil UBL, vol. 6, no. 2, 2015, doi: 10.23917/warta.v23i1.10202. 
[16] D. S. Putra, N. Djali, and Rahmat, "PERENCANAAN BANGUNAN PENANGKAP SEDIMEN (CHECK DAM) DI HULU BATANG KURANJI,” 2012.

[17] I. M. Kamiana, "Teknik Perhitungan Debit Rencana Bangunan Air," Yogyakarta Graha Ilmu, 2010.

[18] Hermanto, M. Samah, and I. Khaidir, "PERENCANAAN CHECKDAM DURIAN TARUNG KOTAPADANG," Bung Hatta Univ.

[19] S. M. Janosik, "PERENCANAAN CHECK DAM DAS LUSI DI KABUPATEN BLORA,” J. Karya Tek. Sipil, vol. 3, no. 4, 2014, doi: 10.1017/CBO9781107415324.004.

[20] S. M. Sari, R. Fayunta, J. Hadihardaja, and Suharyanto, "PERENCANAAN KONSERVASI DAS BRINGIN BAGIAN HULU DENGAN CHECK DAM DAN SUMUR RESAPAN,” J. Karya Tek. Sipil, vol. 2, no. 1, pp. 228-238, 2013. 